\title{
A FOUNDATION FOR INFORMED NEGOTIATION
}

\author{
John Debenham and Simeon Simoff \\ University of Technology, Sydney \\ PO Box 123, Broadway, NSW 2007, Australia \\ Email: $\{$ debenham, simeon $\} @$ it.uts.edu.au
}

Keywords: Intelligent Agents, Decision Support, Agents for Internet Computing.

Abstract: Approaches to the construction of agents that are to engage in competitive negotiation are often founded on game theory. In such an approach the agents are endowed with utility functions and assumed to be utility optimisers. In practice the utility function is derived in the context of massive uncertainties both in terms of the agent's priorities and of the raw data or information. To address this issue we propose an agent architecture that is founded on information theory, and that manages uncertainty with entropy-based inference. Our negotiating agent engages in multi-issue bilateral negotiation in a dynamic information-rich environment. The agent strives to make informed decisions. The agent may assume that the integrity of some of its information decays with time, and that a negotiation may break down under certain conditions. The agent makes no assumptions about the internals of its opponent - it focuses only on the signals that it receives. It constructs two probability distributions over the set of all deals. First the probability that its opponent will accept a deal, and second that a deal will prove to be acceptable to it in time.

\section{INTRODUCTION}

We propose an agent architecture that is founded on information theory, and that manages uncertainty with entropy-based inference. This architecture aims to address the problem of defining a utility function for a game-theoretic agent in the context of massive uncertainties both in terms of the agent's priorities and of the raw data or information. Our agent does not necessarily have a utility function and so is not necessarily a utility optimiser - it may have less selfish aims such as simply 'playing fair'. This Negotiating Agent, $N A$, engages in bilateral bargaining with an opponent, $O P$. It strives to make informed decisions in an information-rich environment that includes market data and general sources including the Internet. $N A$ attempts to fuse the negotiation with the information generated both by and because of it. It reacts to information derived from its opponent and from the environment, and proactively seeks missing information that may be of value.

$N A$ is founded on information theory. Game theory tells us what to do, and what outcome to expect, in many well-known negotiation situations, but these strategies and expectations are derived from assump- tions about the internals of the opponent. Game theoretic analyses of bargaining are founded on the notion of agents as utility optimizers in the presence of complete and incomplete information about their opponents (Muthoo, 1999). Two probability distributions form the foundation of both the offer evaluation and the offer making processes. They are both over the set of all deals and are based on all information available to the agent. The first distribution is the probability that any deal is acceptable to $O P$. The second distribution is the probability that any deal will prove to be acceptable to $N A$ - this distribution generalizes the notion of utility.

$N A$ makes no assumptions about the internals of $O P$ in particular whether it has a utility function. $N A$ does make assumptions about: the way in which the integrity of information will decay, preferences that its opponent may have for some deals over others, and conditions that may lead to breakdown. It also assumes that unknown probabilities can be inferred using maximum entropy probabilistic logic (MacKay, 2003) that is based on random worlds (Halpern, 2003). The maximum entropy probability distribution is "the least biased estimate possible on the given information; i.e. it is maximally noncommittal with 
regard to missing information" (Jaynes, 1957). In the absence of knowledge about $O P$ 's decision-making apparatus, $N A$ assumes that the "maximally noncommittal" model is the correct model on which to base its reasoning.

A preference relation is an assumption that $N A$ makes about $O P$ 's preferences for some deals over others. For example, that she prefers to pay a lower price to a higher price. A single-issue preference relation assumes that she prefers deals on the basis of one issue alone, independent of the values of the other issues. A preference relation may be assumed prior to the negotiation, or during it based on the offers made. For example, the opponent may display a preference for items of a certain color; (Faratin et al., 2003) describes a basis for ordering colors. The preference relations illustrated here are single-issue orderings, but the agent's reasoning operates equally well with any preference relation as long as it may be expressed in Horn clause logic.

Bilateral bargaining is known to be inherently inefficient (Myerson and Satterthwaite, 1983). (Bulow and Klemperer, 1996) shows that a seller is better off with an auction that attracts $n+1$ buyers than bargaining with $n$ individuals, no matter what the bargaining protocol is. (Neeman and Vulkan, 2000) shows that the weaker bargaining types will fare better in exchanges leading to a gradual migration. These results hold for agents who aim to optimize their utility and do limit the work described here.

\section{INFORMED AGENTS}

$N A$ operates in an information-rich environment. The integrity of its information, including information extracted from the Internet, will decay in time. The way in which this decay occurs will depend on the type of information, and on the source from which it is drawn. Little appears to be known about how the integrity of information, such as news-feeds, decays.

One source of $N A$ 's information is the signals received from $O P$. These include offers to $N A$, and the acceptance or rejection of $N A$ 's offers. If $O P$ rejected $N A$ 's offer of $\$ 8$ two days ago then what is $N A$ 's belief now in the proposition that $O P$ will accept another offer of $\$ 8$ now? Perhaps it is around 0.1. A linear model is used to model the integrity decay of these beliefs, and when the probability of a decaying belief approaches $0.5^{1}$ the belief is discarded. This choice of a linear model is independent of the bargaining method. The model of decay could be exponential, quadratic or what ever.

\footnotetext{
${ }^{\prime} \mathrm{A}$ sentence probability of 0.5 represents "maybe, maybe not".
}

\subsection{Interaction Protocol}

The agents communicate using sentences in a firstorder language $\mathcal{L}$. This includes the exchange, acceptance and rejection of offers. $\mathcal{L}$ contains the following predicates: $O f f e r(\delta), \operatorname{Accept}(\delta), \operatorname{Reject}(\delta)$ and Quit $($.$) , where Offer (\delta)$ means "the sender is offering you a deal $\delta$ ", Accept $(\delta)$ means "the sender accepts your deal $\delta$ ", Reject $(\delta)$ means "the sender rejects your deal $\delta$ " and Quit(.) means "the sender quits - the negotiation ends".

Two negotiation protocols are described. First, negotiation without decay in which all offers stand for the entire negotiation. Second, negotiation with decay in which offers stand only if accepted by return - NA represents $O P$ 's offers as beliefs with sentence probabilities that decay in time.

$N A$ and $O P$ each exchange offers alternately at successive discrete times (Kraus, 2001). They enter into a commitment if one of them accepts a standing offer. The protocol has three stages:

1. Simultaneous, initial, binding offers from both agents;

2. A sequence of alternating offers, and

3. An agent quits and walks away from the negotiation.

The negotiation ceases either in the second round if one of the agents accepts a standing offer or in the final round if one agent quits and the negotiation breaks down.

In the first stage the agents simultaneously send $O f$ fer(.) messages to each other. These initial offers are taken as limits on the range of values that are considered possible. This is crucial to the method described in Sec. 3 where there are domains that would otherwise be unbounded. The exchange of initial offers "stakes out the turf" on which the subsequent negotiation will take place. In the second stage an Offer(.) message is interpreted as an implicit rejection, Reject(.), of the opponent's offer on the table.

\subsection{Agent Architecture}

Incoming messages from all sources are timestamped and placed in an "In Box", $\mathcal{X}$, as they arrive. $N A$ has a knowledge base $\mathcal{K}$ and a belief set $\mathcal{B}$. Each of these two sets contains statements in $\mathcal{L}$. $\mathcal{K}$ contains statements that are generally true, such as $\forall x(\operatorname{Accept}(x) \leftrightarrow \neg \operatorname{Reject}(x))-$ i.e. an agent does one thing or the other. The belief set $\mathcal{B}=\left\{\beta_{i}\right\}$ contains statements that are each qualified with a given sentence probability, $\mathbf{B}\left(\beta_{i}\right)$, that represents an agent's belief in the truth of the statement. These sentence probabilities may decay in time.

The distinction between the knowledge base $\mathcal{K}$ and the belief set $\mathcal{B}$ is simply that $\mathcal{K}$ contains unqualified 
statements and $\mathcal{B}$ contains statements that are quali fied with sentence probabilities. $\mathcal{K}$ and $\mathcal{B}$ play different roles in the method described in Sec. 3.

$N A$ 's actions are determined by its "strategy". A strategy is a function $\mathbf{S}: \mathcal{K} \times \mathcal{B} \rightarrow \mathcal{A}$ where $\mathcal{A}$ is the set of actions. At certain distinct times the function $\mathbf{S}$ is applied to $\mathcal{K}$ and $\mathcal{B}$ and the agent does something. The set of actions, $\mathcal{A}$, includes sending Offer(.), Accept (.), Reject (.) and Quit(.) messages to $O P$. The way in which $\mathbf{S}$ works is described in Sec. 5. Momentarily before the $\mathbf{S}$ function is activated, a "revision function" $\mathbf{R}$ is activated:

$\mathbf{R}:(\mathcal{X} \times \mathcal{K} \times \mathcal{B}) \rightarrow(\mathcal{K} \times \mathcal{B})$

$\mathbf{R}$ clears the "In Box", and stores the messages either in $\mathcal{B}$ with a given sentence probability or in $\mathcal{K}$.

A deal, $\delta$, is a commitment for the sender to do something, $\tau$ (the sender's "terms"), subject to the receiver committing to do something, $\omega$ (the receiver's "terms"): $\delta=(\tau, \omega)$. NA may have a real-valued utility function: $\mathbf{U}: \mathcal{T} \rightarrow \Re$, where $\mathcal{T}$ is the set of terms. If so, then for any deal $\delta=(\tau, \omega)$ the expression $\mathbf{U}(\omega)-\mathbf{U}(\tau)$ is called the surplus of $\delta$. An agent may be unable to specify a utility function either precisely or with certainty. ${ }^{2}$ Sec. 4 describes a predicate $N A A C C$.) that represents the "acceptability" of a deal.

$N A$ uses three things to make offers: an estimate of the likelihood that $O P$ will accept any offer [Sec. 3], an estimate of the likelihood that $N A$ will, in hindsight, feel comfortable accepting any particular offer [Sec. 4], and an estimate of when $O P$ may quit and leave the negotiation [Sec. 5].

\subsection{Random Worlds}

Let $\mathcal{G}$ be the set of all positive ground literals that can be constructed using the predicate, function and constant symbols in $\mathcal{L}$. A possible world is a valuation function $\mathbf{v}: \mathcal{G} \rightarrow\{T, \perp\}$. V denotes the set of all possible worlds, and $V_{\mathcal{K}}$ denotes the set of possible worlds that are consistent with a knowledge base $\mathcal{K}$ (Halpern, 2003).

A random world for $\mathcal{K}$ is a probability distribution $\mathbf{W}_{\mathcal{K}}=\left\{p_{i}\right\}$ over $\mathbf{V}_{\mathcal{K}}=\left\{\mathbf{v}_{i}\right\}$, where $\mathbf{W}_{\mathcal{K}}$ expresses an agent's degree of belief that each of the possible worlds is the actual world. The derived sentence probability of any $\sigma \in \mathcal{L}$, with respect to a random world $\mathbf{W}_{\mathcal{K}}$ is:

$$
\mathbf{P}_{\mathbf{W}_{\mathcal{K}}}(\sigma) \triangleq \sum_{n}\left\{p_{n}: \sigma \text { is } T \text { in } \mathbf{v}_{n}\right\}
$$

A random world $\mathbf{W}_{\mathcal{K}}$ is consistent with the agent's beliefs $\mathcal{B}$ if: $(\forall \beta \in \mathcal{B})\left(\mathbf{B}(\beta)=\mathbf{P}_{\mathbf{w}_{\mathcal{K}}}(\beta)\right)$. That

\footnotetext{
${ }^{2}$ The often-quoted oxymoron "I paid too much for it, but its worth it." attributed to Samuel Goldwyn, movie producer, illustrates that intelligent agents may choose to negotiate with uncertain utility.
}

is, for each belief its derived sentence probability as calculated using Eqn. 1 is equal to its given sentence probability.

The entropy of a discrete random variable $X$ with probability mass function $\left\{p_{i}\right\}$ is (MacKay, 2003): $H(X)=-\sum_{n} p_{n} \log p_{n}$ where: $p_{n} \geq 0$ and $\sum_{n} p_{n}=1$. Let $\mathbf{W}_{\{\mathcal{K}, \mathcal{B}\}}$ be the "maximum entropy probability distribution over $\mathbf{V}_{\mathcal{K}}$ that is consistent with $\mathcal{B}$ ". Given an agent with $\mathcal{K}$ and $\mathcal{B}$, its derived sentence probability for any sentence, $\sigma \in \mathcal{L}$, is:

$$
(\forall \sigma \in \mathcal{L}) \mathbf{P}(\sigma) \triangleq \mathbf{P}_{\mathbf{W}_{\{\mathcal{K} . \mathcal{B}\}}}(\sigma)
$$

Using Eqn. 2, the derived sentence probability for any belief, $\beta_{i}$, is equal to its given sentence probability. So the term sentence probability is used without ambiguity.

\section{ESTIMATING P $($ OPAcc $()$.}

$N A$ does two different things. First, it reacts to offers received from $O P$ - that is described in Sec. 4. Second, it sends offers to $O P$. This section describes the estimation of $\mathbf{P}(O P A c c(\delta))$ where the predicate $O P A C c(\delta)$ means "the deal $\delta$ is acceptable to $O P$ ".

When a negotiation commences $N A$ may have no information about $O P$ or about prior deals. If so then the initial offers may only be based on past experience or circumstantial information. ${ }^{3}$ So the opening offers are simply taken as given.

In the four sub-sections following, $N A$ is attempting sell something to $O P$. In Secs. 3.1 and $3.2 N A$ 's terms $\tau$ are to supply a particular good, and $O P$ 's terms $\omega$ are money - in those examples the amount of money $\omega$ is the subject of the negotiation. In Secs. 3.3 and $3.4 \mathrm{NA}$ 's terms are to supply a particular good together with some negotiated warranty period, and $O P$ 's terms are money - in those examples the amount of money $p$ and the period of the warranty period $w$ are the subject of the negotiation.

\subsection{One Issue - Without Decay}

The unary predicate $O P A C C(x)$ means "the amount of money $\$ x$ is acceptable to $O P$ ". $N A$ is interested in whether the unary predicate $O P A c c(x)$ is true for various values of $\$ x$. NA assumes the following preference relation on the $O P A c c$ predicate: $\kappa_{1}: \forall x, y((x>y) \rightarrow(\operatorname{OPAcc}(x) \rightarrow \operatorname{OPACc}(y)))$

\footnotetext{
${ }^{3}$ In rather dire circumstances King Richard III of England is reported to have initiated a negotiation with remarkably high stakes: "A horse! a horse! my kingdom for a horse!" [William Shakespeare]. Fortunately for Richard, a person named Catesby was nearby, and advised Richard to retract this rash offer "Withdraw, my lord", and so Richard's intention to honor his commitments was not put to the test.
} 
Suppose that NA's opening offer is $\bar{\omega}$, and $O P$ 's opening offer is $\underline{\omega}$ where $\underline{\omega}<\bar{\omega}$. Then $\mathcal{K}$ now contains two further sentences: $\kappa_{2}: \neg \operatorname{OPAcc}(\bar{\omega})$ and $\kappa_{3}: \operatorname{OPACC}(\underline{\omega})$. There are now $\bar{\omega}-\underline{\omega}$ possible worlds, and the maximum entropy distribution is uniform.

Suppose that NA knows its true valuation for the good, $u_{n a}$, and that $N A$ has decided to make an "expected-utility-optimizing" offer: $x=\frac{\bar{\omega}+u_{u n}}{2}$. This offer is calculated on the basis of the preference ordering $\kappa_{1}$ and the two signals that $N A$ has received from $O P$. The response is in terms of only $N A$ 's valuation $u_{n n}$ and the signal $\operatorname{Reject}(\bar{\omega})$ - it is independent of the signal Offer $(\underline{\omega})$ which implies that $\underline{\omega}$ is acceptable.

In the standard game theoretic analysis of bargaining (Muthoo, 1999), NA assumes that $O P$ has a utility, $u_{o p}$, that it lies in some interval $[\underline{u}, \bar{u}]$, and that the expected value of $u_{o p}$ is uniformly distributed on that interval. On the basis of these assumptions $N A$ then derives the expected-utility-optimizing offer: $\frac{\bar{u}+u_{n n}}{2}$. These two offers differ by $\bar{u}$ in the game-theoretic result and $\bar{\omega}$ in the maximum entropy result. The game theoretic approach relies on estimates for $\underline{u}$ and $\bar{u}$ : $\mathbf{E}([\underline{u}, \bar{u}] \mid \operatorname{Reject}(\bar{\omega}) \wedge \operatorname{Accept}(\underline{\omega}))$

If $O P$ has a utility, and it may not, then if $O P$ is rational: $\underline{u} \leq \underline{\omega} \leq \bar{u}$. The inherent inefficiency of bilateral bargaining (Myerson and Satterthwaite, 1983) shows for an economically rational $O P$ that $u_{o p}$, and so consequently $\bar{u}$, may be greater than $\bar{\omega}$. There is no reason to suspect that $\bar{u}$ and $\bar{\omega}$ will be equal.

\subsection{One Issue - With Decay}

As in the previous example, suppose that the opening offers at time $t_{0}$ are taken as given and are $\underline{\omega}$ and $\bar{\omega}$. Then $\mathcal{K}$ contains $\kappa_{1}, \kappa_{2}$ and $\kappa_{3}$. Suppose $\mathcal{L}$ contains $n$ consecutive, integer constants in the interval $[\underline{\omega}, \bar{\omega}]$, where $n=\bar{\omega}-\underline{\omega}+1$, that represent various amounts of money. $\kappa_{1}$ induces a total ordering on the sentence probabilities for $\operatorname{OPAcc}(x)$ on the interval $[\underline{\omega}, \bar{\omega}]$, where the probabilities are $\approx 0$ at $\bar{\omega}$, and $\approx 1$ at $\underline{\omega}$.

Suppose that at time $t_{1} N A$ makes an offer $\omega_{n a}$ which is rejected by $O P$, who has replied at time $t_{2}$ with an offer of $\omega_{o p}$ where $\underline{\omega} \leq \omega_{o p} \leq \omega_{n a} \leq \bar{\omega}$. At time $t_{3} \mathcal{B}$ contains $\beta_{1}: \operatorname{OPACc}\left(\omega_{n a}\right)$ and $\beta_{2}$ : $\operatorname{OPAcc}\left(\omega_{o p}\right)$. Suppose that there is some level of integrity decay on these two beliefs: $0<\mathbf{B}\left(\beta_{1}\right)<$ $0.5<\mathbf{B}\left(\beta_{2}\right)<1$. Then $\mathbf{V}_{\mathcal{K}}$ contains $n+1$ possible worlds ranging from "all false" to "all true" each containing $n$ literals. So a random world for $\mathcal{K}$ will consist of $n+1$ probabilities $\left\{p_{i}\right\}$, where, say, $p_{1}$ is the probability of "all true", and $p_{n+1}$ is the probability of "all false". $\mathbf{P}_{\{\mathcal{K}, \mathcal{B}\}}$ will be the distribution that maximizes $-\sum_{n} p_{n} \log p_{n}$ subject to the constraints: $p_{n} \geq 0, \sum_{n} p_{n}=1, \sum_{n=1}^{\bar{\omega}-\omega_{n a}+1} p_{n}=\mathbf{B}\left(\beta_{1}\right)$ and $\sum_{n=1}^{\bar{\omega}-\omega_{o p}+1} p_{n}=\mathbf{B}\left(\beta_{2}\right)$

The optimization of entropy, $H$, subject to linear constraints is described in Sec. 3.2.1 below. $\mathbf{P}_{\{\mathcal{K}, \mathcal{B}\}}$ is:

$$
p_{n}=
$$$$
\left\{\begin{array}{l}
\frac{\mathbf{B}\left(\beta_{1}\right)}{\overline{\bar{\omega}}-\omega_{n a}+1} \\
\frac{\mathbf{B}\left(\beta_{2}\right)-\mathbf{B}\left(\beta_{1}\right)}{\omega_{n a}-\omega_{o p}} \\
\frac{1-\mathbf{B}\left(\beta_{2}\right)}{\omega_{o p}-\underline{\omega}+1}
\end{array}\right.
$$

$$
\begin{aligned}
& \text { if } 1 \leq n \leq \bar{\omega}-\omega_{n a}+1 \\
& \text { if } \bar{\omega}-\omega_{n a}+1<n<\bar{\omega}-\omega_{o p}+2 \\
& \text { if } \bar{\omega}-\omega_{o p}+2 \leq n \leq \bar{\omega}-\underline{\omega}+2
\end{aligned}
$$

Using Eqn. 2, for $\omega_{o p} \leq x \leq \omega_{n a}$ :

$$
\begin{aligned}
& \mathbf{P}(\operatorname{OPACC}(x))= \\
& \mathbf{B}\left(\beta_{1}\right)+\frac{\omega_{n a}-x}{\omega_{n a}-\omega_{o p}}\left(\mathbf{B}\left(\beta_{2}\right)-\mathbf{B}\left(\beta_{1}\right)\right)
\end{aligned}
$$

These probability estimates are used in Sec. 5 to calculate $N A$ 's next offer.

The values for $\mathbf{P}(O P A c c(x))$ in the region $\omega_{o p} \leq$ $x \leq \omega_{n a}$ are derived from only two pieces of information that are the two signals $\operatorname{Reject}\left(\omega_{n a}\right)$ and $\operatorname{Offer}\left(\omega_{o p}\right)$ each qualified with the time at which they arrived, and the decay rate on their integrity. The assumptions in the analysis given above are: the choice of values for $\underline{\omega}$ and $\bar{\omega}-$ which do not appear in Eqn. 3 in any case - and the choice of the "maximally noncommittal" distribution.

If the agents continue to exchange offers then new beliefs will be acquired and the integrity of old beliefs will decay. If the next pair of offers lies within the interval $\left[\omega_{o p}, \omega_{n a}\right]$ and if the integrity of $\beta_{1}$ and $\beta_{2}$ decays then the sentence probabilities of $\beta_{1}$ and $\beta_{2}$ will be inconsistent with those of the two new beliefs due to the total ordering of sentence probabilities on $[\underline{\omega}, \bar{\omega}]$ induced by $\kappa_{1}$. This inconsistency is resolved by the revision function $\mathbf{R}$ that here discards inconsistent older beliefs, $\beta_{1}$ and $\beta_{2}$, in favor of more recent beliefs. If the agents continue in this way then the sentence probabilities for the OPACc predicate are given simply by Eqn. 3 using the most recent values for $\omega_{n a}$ and $\omega_{o p}$.

The analysis given above requires that values be specified for the opening offers $\underline{\omega}$ and $\bar{\omega}$. The only part of the probability distribution that depends on the values chosen for $\underline{\omega}$ and $\bar{\omega}$ are the two "tails" of the distribution. So the choice of values for these two opening offers is unlikely to effect the estimates. The two tails are necessary to "soak up" the otherwise unallocated probability.

\subsubsection{Maximizing Entropy}

If $X$ is a discrete random variable taking a finite number of possible values $\left\{x_{i}\right\}$ with probabilities $\left\{p_{i}\right\}$ then the entropy is the average uncertainty removed by discovering the true value of $X$, and is given by $H=-\sum_{n} p_{n} \log p_{n}$. The direct optimization of 
$H$ subject to a number, $\theta$, of linear constraints of the form $\sum_{n} p_{n} g_{k}\left(x_{n}\right)=\bar{g}_{k}$ for given constants $\bar{g}_{k}$, where $k=1, \ldots, \theta$, is a difficult problem. Fortunately this problem has the same unique solution as the maximum likelihood problem for the Gibbs distribution (Pietra et al., 1997). The solution to both problems is given by:

$$
p_{n}=\frac{\exp \left(-\sum_{k=1}^{\theta} \lambda_{k} g_{k}\left(x_{n}\right)\right)}{\sum_{m} \exp \left(-\sum_{k=1}^{\theta} \lambda_{k} g_{k}\left(x_{m}\right)\right)}
$$

for $n=1,2, \cdots$, where the constants $\left\{\lambda_{i}\right\}$ may be calculated using Eqn. 4 together with the three sets of constraints: $p_{n} \geq 0, \sum_{n} p_{n}=1$ and $\sum_{n} p_{n} g_{k}\left(x_{n}\right)=\bar{g}_{k}$. The distribution in Eqn. 4 is known as Gibbs distribution.

Calculating the expressions for the values of $\left\{p_{n}\right\}$ given in the example above in Sec. 3.2 does not require the full evaluation of the expressions in Eqn. 4 That equation shows that there are just three different values for the $\left\{p_{n}\right\}$. Applying simple algebra to that fact together with the constraints yields the expressions given.

\subsection{Two Issues - Without Decay}

The above approach to single-issue bargaining generalizes without modification to multi-issue bargaining, it is illustrated with two issues only for ease of presentation. The problem considered is the sale of an item with $0, \ldots, 4$ years of warranty. The terms being negotiated specify an amount of money $p$ and the number of years warranty $w$. The predicate $\operatorname{OPAcc}(w, p)$ now means " $O P$ will accept the offer to purchase the good with $w$ years warranty for $\$ p$ ".

$N A$ assumes the following two preference orderings, and $\mathcal{K}$ contains:

$$
\begin{gathered}
\kappa_{11}: \forall x, y, z((x>y) \rightarrow(\operatorname{OPAcc}(y, z) \rightarrow \\
\quad \text { OPACc }(x, z))) \\
\kappa_{12}: \forall x, y, z((x>y) \rightarrow(\operatorname{OPACC}(z, x) \rightarrow \\
\operatorname{OPACC}(z, y)))
\end{gathered}
$$

As in Sec. 3.1, these sentences conveniently reduce the number of possible worlds. The number of possible worlds will be finite as long as $\mathcal{K}$ contains two statements of the form: $\neg O P A c c(4, a)$ and $O P A C c(0, b)$ for some $a$ and $b$. Suppose that NA's initial offer was "4 years warranty for $\$ 21$ " and $O P$ 's initial offer was "no warranty for $\$ 10$ ". $\mathcal{K}$ now contains:

$\kappa_{13}: \neg \operatorname{OPAcc}(4,21) \quad \kappa_{14}: \operatorname{OPAcc}(0,10)$

These two statements, together with the restriction to integers only, limit the possible values of $w$ and $p$ in $\operatorname{OPAcc}(w, p)$ to a $5 \times 10$ matrix.

Suppose that NA knows its utility function for the good with $0, \ldots, 4$ years warranty and that its values are: $\$ 11.00, \$ 11.50, \$ 12.00, \$ 13.00$ and $\$ 14.50$ respectively. Suppose that $N A$ uses the strategy $\mathbf{S}^{(n)}$ which is described in Sec. 5 - the details of that strategy are not important now. If $N A$ uses that strategy with $n=2$, then $N A$ offers $\operatorname{Offer}(2, \$ 16)$ which suppose $O P$ rejects and counters with $O f f e r(1, \$ 11)$. Then with $n=2$ again, $N A$ offers $O$ Offer $(2 . \$ 14)$ which suppose $O P$ rejects and counters with $\operatorname{Offer}(3, \$ 13)$. $\mathbf{P}(\operatorname{OPACC}(w, p))$ now is:

$\begin{array}{llllll} & w=0 & w=1 & w=2 & w=3 & w=4 \\ p=20 & 0.0000 & 0.0000 & 0.0000 & 0.0455 & 0.0909 \\ p=19 & 0.0000 & 0.0000 & 0.0000 & 0.0909 & 0.1818 \\ p=18 & 0.0000 & 0.0000 & 0.0000 & 0.1364 & 0.2727 \\ p=17 & 0.0000 & 0.0000 & 0.0000 & 0.1818 & 0.3636 \\ p=16 & 0.0000 & 0.0000 & 0.0000 & 0.2273 & 0.4545 \\ p=15 & 0.0000 & 0.0000 & 0.0000 & 0.2727 & 0.5454 \\ p=14 & 0.0000 & 0.0000 & 0.0000 & 0.3182 & 0.6364 \\ p=13 & 0.0455 & 0.0909 & 0.1364 & 1.0000 & 1.0000 \\ p=12 & 0.0909 & 0.1818 & 0.2727 & 1.0000 & 1.0000 \\ p=11 & 0.1364 & 1.0000 & 1.0000 & 1.0000 & 1.0000\end{array}$

and the expected-utility-optimizing offer is: $O f$ fer $(4, \$ 18)$. If $N A$ makes that offer then the expected surplus is $\$ 0.95$. The matrix above contains the "maximally non-committal" values for $\mathbf{P}(O P A c c(w, p))$; those values are recalculated each time a signal arrives. The example demonstrates how the NA is able to conduct multi-issue bargaining in a focussed way without making assumptions about $O P$ 's internals, in particular, whether $O P$ is aware of a utility function (Osborne and Rubinstein, 1990).

\subsection{Two Issues - With Decay}

Following from the previous section, suppose that $\mathcal{K}$ contains $\kappa_{11}, \kappa_{12}, \kappa_{13}$ and $\kappa_{14}$. The two preference orderings $\kappa_{11}$ and $\kappa_{12}$ induce a partial ordering on the sentence probabilities in the $\mathbf{P}(\operatorname{OPAcc}(w, p))$ array [as in Sec. 3.3] from the top-left where the probabilities are $\approx 0$, to the bottom-right where the probabilities are $\approx 1$. There are fifty-one possible worlds that are consistent with $\mathcal{K}$.

Suppose that $\mathcal{B}$ contains: $\beta_{11}$ : $\operatorname{OPAcc}(2,16)$, $\beta_{12}: \operatorname{OPACc}(2,14), \beta_{13}: \operatorname{OPACC}(1,11)$ and $\beta_{14}$ $\operatorname{OPAcc}(3,13)$ - this is the same offer sequence as considered in Sec. 3.3 - and with a $10 \%$ decay in integrity for each time step: $\mathbf{P}\left(\beta_{11}\right)=0.4, \mathbf{P}\left(\beta_{12}\right)=$ $0.2, \mathbf{P}\left(\beta_{13}\right)=0.7$ and $\mathbf{P}\left(\beta_{14}\right)=0.9$. Belief $\beta_{11}$ is inconsistent with $\mathcal{K} \cup\left\{\beta_{12}\right\}$ as together they violate the sentence probability ordering induced by $\kappa_{11}$ and $\kappa_{12}$. Resolving this issue is a job for the belief revision function $\mathbf{R}$ which discards the older, and weaker, belief $\beta_{11}$.

Eqn. 4 is used to calculate the distribution $W_{\{\mathcal{K}, \mathcal{B}\}}$ which has just five different probabilities in it. The resulting values for the three $\lambda^{\prime}$ 's are: $\lambda_{12}=$ 2.8063, $\lambda_{13}=-2.0573$ and $\lambda_{14}=-2.5763$. 
$\mathbf{P}(\operatorname{OPACC}(w, p))$ now is:

$\begin{array}{llllll} & w=0 & w=1 & w=2 & w=3 & w=4 \\ p=20 & 0.0134 & 0.0269 & 0.0286 & 0.0570 & 0.0591 \\ p=19 & 0.0269 & 0.0537 & 0.0571 & 0.1139 & 0.1183 \\ p=18 & 0.0403 & 0.0806 & 0.0857 & 0.1709 & 0.1774 \\ p=17 & 0.0537 & 0.1074 & 0.1143 & 0.2279 & 0.2365 \\ p=16 & 0.0671 & 0.1343 & 0.1429 & 0.2849 & 0.2957 \\ p=15 & 0.0806 & 0.1611 & 0.1714 & 0.3418 & 0.3548 \\ p=14 & 0.0940 & 0.1880 & \mathbf{0 . 2 0 0 0} & 0.3988 & 0.4139 \\ p=13 & 0.3162 & 0.6324 & 0.6728 & \mathbf{0 . 9 0 0 0} & 0.9173 \\ p=12 & 0.3331 & 0.6662 & 0.7088 & 0.9381 & 0.9576 \\ p=11 & 0.3500 & \mathbf{0 . 7 0 0 0} & 0.7447 & 0.9762 & 0.9978\end{array}$

In this array, the derived sentence probabilities for the three sentences in $\mathcal{B}$ are shown in bold type; they are exactly their given values.

\section{ESTIMATING P(NAAcc $()$.}

The proposition $N A A c c(\delta)$ means: " $\delta$ is acceptable to $N A$ ". This section describes how $N A$ attaches a conditional probability to the proposition: $\mathbf{P}(N A A c c(\delta)$ | $\left.\mathcal{I}_{t}\right)$ in the light of information $\mathcal{I}_{t}$. The meaning of "acceptable to $N A$ " is described below. This is intended to put $N A$ in the position "looking back on it, I made the right decision at the time" - this is a vague notion but makes sense to the author. The idea is for NA to accept a deal $\delta$ when $\mathbf{P}\left(N A A c c(\delta) \mid \mathcal{I}_{t}\right) \geq \alpha$ for some threshold value $\alpha$ that is one of NA's mental states.

$\mathbf{P}\left(\operatorname{NAACC}(\delta) \mid \mathcal{I}_{t}\right)$ is derived from conditional probabilities attached to four other propositions: $\mathbf{P}\left(\operatorname{Suited}(\omega) \mid \mathcal{I}_{t}\right)$,

$\mathbf{P}\left(\operatorname{Good}(O P) \mid \mathcal{I}_{t}\right)$,

$\mathbf{P}\left(\operatorname{Fair}(\delta) \mid \mathcal{I}_{t} \cup\{\right.$ Suited $\left.(\omega), \operatorname{Good}(O P)\}\right)$ and

$\mathbf{P}(\operatorname{Me}(\delta) \mid \mathcal{I}, \cup\{$ Suited $(\omega), \operatorname{Good}(O P)\})$.

meaning respectively: "terms $\omega$ are perfectly suited to my needs", "OP will be a good agent for me to be doing business with", " $\delta$ is generally considered to be a good deal for $N A$ ", and "on strictly subjective grounds, $\delta$ is acceptable to $N A$ ". The last two of these four probabilities factor out both the suitability of $\omega$ and the appropriateness of the opponent $O P$. The difference between the third and fourth is that the third captures the concept of "a good market deal" and the fourth a strictly subjective "what $\omega$ is worth to $N A$ ". The "Me(.)" proposition is related to the concept of a private valuation in game theory.

To determine $\mathbf{P}\left(\right.$ Suited $\left.(\omega) \mid \mathcal{I}_{t}\right)$. If there are sufficiently strong preference relations to establish extrema for this distribution then they may be assigned extreme values $\approx 0.0$ or 1.0 . NA is repeatedly asked to provide probability estimates for the offer $\omega$ that yields the greatest reduction in entropy for the resulting distribution (MacKay, 2003). This continues until NA considers the distribution to be "satisfactory". This is tedious but the "preference acquisition bot- tleneck" appears to be an inherently costly business (Castro-Schez et al., 2004).

To determine $\mathbf{P}\left(\operatorname{Good}(O P) \mid \mathcal{I}_{t}\right)$ involves an assessment of the reliability of $O P$. For some retailers (sellers), information - of varying reliability - may be extracted from sites that rate them. For individuals, this may be done either through assessing their reputation established during prior trades (Ramchurn et al., 2003) (Sierra and Debenham, 2005), or by the inclusion of some third-party escrow service that is then rated for "reliability" instead.

$\mathbf{P}\left(\operatorname{Fair}(\delta) \mid \mathcal{I}_{t} \cup\{\right.$ Suited $\left.(\omega), \operatorname{Good}(O P)\}\right)$ is determined by market data. As for dealing with Suited, if the preference relations establish extrema for this distribution then extreme values may be assigned. Independently of this, real market data, qualified with given sentence probabilities, is fed into the distribution. The revision function $\mathbf{R}$ identifies and removes inconsistencies, and missing values are estimated using the maximum entropy distribution.

Determining $\mathbf{P}\left(M e(\delta) \quad \mid \mathcal{I}_{1} \cup\{\right.$ Suited $(\omega)$, $\operatorname{Good}(O P)\})$ is a subjective matter. It is specified using the same device as used for Fair except that the data is fed in by hand "until the distribution appears satisfactory". To start this process first identify those $\delta$ that "NA would be never accept" - they are given a probability of $\approx 0.0$, and second those $\delta$ that "NA would be delighted to accept" - they are given a probability of $\approx 1.0$. The $M e$ proposition links the information-theory approach with "private valuations" in game-theory.

There is no causal relationship between the four probability distributions as they have been defined, with the possible exception of the third and fourth. To link the probabilities associated with the five propositions, the probabilities are treated as epistemic probabilities and the nodes form a simple Bayesian net. The weights on the four arcs of the Bayesian net are a subjective representation of what "acceptable" means to $N A$. The resulting net divides the problem of estimating $\mathbf{P}(N A A c c)$ into four simpler sub-problems.

The conditionals on the Bayesian network are subjective - they are easy to specify because twelve of them are zero - that is, for the cases in which $N A$ believes that either $M e$ or Suited is "false". For example, if the conditionals (set by NA) are:

$\mathbf{P}($ NAAcc $\mid$ Me, Suited, Good, Fair $)=1.0$

$\mathbf{P}($ NAAcc $\mid$ Me, Suited, $\neg$ Good, Fair $)=0.1$

$\mathbf{P}($ NAAcc $\mid$ Me, Suited, Good, $\neg$ Fair $)=0.4$

$\mathbf{P}($ NAACc $\mid$ Me, Suited, $\neg$ Good, $\neg$ Fair $)=0.05$

then, with probabilities of 0.9 on each of the four evidence nodes, the probability $\mathbf{P}(N A A C c)=0.75$. It then remains to manage the acquisition of information $\mathcal{I}_{t}$ from the available sources to, if necessary, increase $\mathbf{P}\left(\operatorname{NAACC}(\delta) \mid \mathcal{I}_{t}\right)$ so that $\delta$ is acceptable. The conditional probabilities on the net represent an agent's priorities for a deal, and so they are specified for each 
class of deal.

The NAAcc predicate generalizes the notion of utility. Suppose that $N A$ knows its utility function U. If the conditionals on the Bayesian net are as in the previous paragraph and if either $\mathbf{P}(\mathbf{M e}()$.$) or$ $\mathbf{P}($ Suited $()$.$) are zero then \mathbf{P}(N A A C c()$.$) will be zero.$ If the conditional probabilities on the Bayesian net are 1.0 when $M e$ is true and are 0.0 otherwise then $\mathbf{P}(N A A c c)=\mathbf{P}(M e)$. Then define: $\mathbf{P}(M e(\tau, \omega))=$ $\frac{1}{2} \times\left(1+\frac{\mathbf{U}(\omega)-\mathbf{U}(\tau)}{\mathbf{U}(\bar{\omega})-\mathbf{U}(\tau)}\right)$ for $\mathbf{U}(\omega)>\mathbf{U}(\tau)$ and zero otherwise, where $\bar{\omega}=\max _{\omega} \mathrm{U}(\omega) .{ }^{4}$ A bargaining threshold $\alpha>0.5$ will then accept offers for which the surplus is positive. In this way NAACc represents utility-based bargaining with a private valuation.

$N A A C c$ also is intended to be able to represent apparently irrational bargaining situations (eg: "I've just got to have that hat"), as well as tricky multi-issue problems such as those typical in eProcurement. It enables an agent to balance the degree of suitability of the terms offered with the reliability of the opponent and with the fairness of the deal.

\section{NEGOTIATION STRATEGIES}

Sec. 3 estimated the probability distribution, $\mathbf{P}(O P A c c)$, that $O P$ will accept an offer, and Sec. 4 estimated the probability distribution, $\mathbf{P}(N A A c c)$, that $N A$ should be prepared to accept an offer. These two probability distributions represent the opposing interests of the two agents NA and OP. P(OPACc) will change every time an offer is made, rejected or accepted. $\mathbf{P}(N A A C c)$ will change as the background information changes. This section discusses $N A$ 's strategy $\mathbf{S}$.

Bargaining can be a game of bluff and counterbluff in which an agent may even not intend to close the deal if one should be reached. A basic conundrum in any offer-exchange bargaining is: it is impossible to force your opponent to reveal information about their position without revealing information about your own position. Further, by revealing information about your own position you may change your opponents position - and so on. ${ }^{5}$ This infi-

\footnotetext{
${ }^{4}$ The introduction of $\bar{\omega}$ may be avoided by defining $\mathbf{P}(M e(\tau, \omega)) \triangleq \frac{1}{1+\exp (-\beta \times(\mathbf{U}(\omega)-\mathbf{U}(\tau))}$ for $\mathbf{U}(\omega) \geq \mathbf{U}(\tau)$ and zero otherwise, where $\beta$ is some constant. This is the sigmoid transfer function used in some neural networks. This function is near-linear for $\mathbf{U}(\omega) \approx \mathbf{U}(\tau)$, and is concave, or "risk averse", outside that region. The transition between these two behaviors is determined by the choice of $\beta$.

${ }^{5}$ This a reminiscent of Werner Heisenberg's indeterminacy relation, or unbestimmtheitsrelationen: "you can't measure one feature of an object without changing another" - with apologies.
}

nite regress, of speculation and counter-speculation, is avoided here by ignoring the internals of the opponent and by focussing on what is known for certain - that is: what information is contained in the signals received and when did those signals arrive.

A fundamental principle of competitive bargaining is "never reveal your best price", and another is "never reveal your deadline - if you have one" (Sandholm and Vulkan, 1999). It is not possible to be prescriptive about what an agent should reveal. All that can be achieved is to provide strategies that an agent may choose to employ. The following are examples of such strategies.

An agent's strategy $\mathbf{S}$ is a function of the information $\mathcal{I}_{t}$ that is has at time $t$. That information will be represented in the agent's $\mathcal{K}$ and $\mathcal{B}$, and will have been used to calculate $\mathbf{P}($ OPACC) and $\mathbf{P}(N A A C c)$. Simple strategies choose an offer only on the basis of $\mathbf{P}(O P A C c), \mathbf{P}(N A A C c)$ and $\alpha$. The greedy strategy $\mathbf{S}^{+}$chooses $\arg \max _{\delta}\{\mathbf{P}(N A A c c(\delta))$ $\mathbf{P}(\operatorname{OPACc}(\delta)) \gg 0\}$, it is appropriate for an agent that believes $O P$ is desperate to trade. The expected-acceptability-to-NA-optimizing strategy $\mathbf{S}^{*}$ chooses $\arg \max _{\delta}\{\mathbf{P}($ OPAcc $(\delta)) \times \mathbf{P}(N A A C c(\delta))$ $\mathbf{P}(\operatorname{NAACc}(\delta)) \geq \alpha\}$, it is appropriate for a confident agent that is not desperate to trade. The strategy $\mathbf{S}^{-}$ chooses arg $\max _{\delta}\{\mathbf{P}($ OPACc $(\delta)) \mid \mathbf{P}(\operatorname{NAACc}(\delta)) \geq$ $\alpha\}$, it optimizes the likelihood of trade - it is a good strategy for an agent that is keen to trade without compromising its own standards of acceptability.

An approach to issue-tradeoffs is described in (Faratin et al., 2003). The bargaining strategy described there attempts to make an acceptable offer by "walking round" the iso-curve of $N A$ 's previous offer (that has, say, an acceptability of $\alpha_{n a} \geq \alpha$ ) towards $O P$ 's subsequent counter offer. In terms of the machinery described here, an analogue is to use the strategy $\mathbf{S}^{-}: \arg \max _{\delta}\{\mathbf{P}($ OPAcc $(\delta)) \mid \mathbf{P}($ NAACc $(\delta) \mid$ $\left.\left.\mathcal{I}_{t}\right) \gtrsim \alpha_{n a}\right\}$ for $\alpha=\alpha_{n a}$. This is reasonable for an agent that is attempting to be accommodating without compromising its own interests. Presumably such an agent will have a policy for reducing the value $\alpha_{n a}$ if her deals fail to be accepted. The complexity of the strategy in (Faratin et al., 2003) is linear with the number of issues. The strategy described here does not have that property, but it benefits from using $\mathbf{P}($ OPAcc $)$ that contains foot prints of the prior offer sequence - see Sec. 3.4 - in that distribution more recent offers have stronger weights.

\section{CONCLUSIONS}

The negotiating agent achieves its goal of reaching informed decisions whilst making no assumptions about the internals of its opponent. The agent is 
founded on information theory is 'driven' by realtime information flows derived from its environment that includes the Internet. Existing text and data mining bots have been used to feed information into $N A$ in experiments including a negotiation between two agents in an attempt to swap a mobile phone for a digital camera with no cash involved.

$N A$ has five ways of leading a negotiation towards a positive outcome. First, by making more attractive offers to $O P$. Second, by reducing its threshold $\alpha$. Third, by acquiring information to hopefully increase the acceptability of offers received. Fourth, by encouraging $O P$ to submit more attractive offers. Fifth, by encouraging $O P$ to accept $N A$ 's offers. The first two of these have been described. The third has been implemented but is not described here. The remaining two are the realm of argumentation-based negotiation which is the next step in this project. The integrated way in which $N A$ manages both the negotiation and the information acquisition should provide a sound basis for an argumentation-based negotiator.

(Halpern, 2003) discusses problems with the random-worlds approach, and notes particularly representation and learning. Representation is particularly significant here - for example, the logical constants in the price domains could have been given other values, and, as long as they remained ordered, and as long as the input values remained unchanged, the probability distributions would be unaltered. Learning is not an issue now as the distributions are kept as simple as possible and are re-computed each time step. The assumptions of maximum entropy probabilistic logic exploit the agent's limited rationality by attempting to assume "precisely no more than is known". But, the computations involved will be substantial if the domains in the language $\mathcal{L}$ are large, and will be infeasible if the domains are unbounded. If the domains are large then preference relations such as $\kappa_{1}$ can simplify the computations substantially.

Much has not been described here including: the data and text mining software, the use of the Bayesian net to prompt a search for information that may lead to $N A$ raising - or perhaps lowering - its acceptability threshold, and the way in which the incoming information is structured to enable its orderly acquisition (Debenham, 2004). We have not described the belief revision and the identification of those random worlds that are consistent with $\mathcal{K}$.

The following issues are presently being investigated. The random worlds computations are performed each time the knowledge, $\mathcal{K}$, or beliefs, $\mathcal{B}$, alter - there is scope for using approximate updating techniques interspersed with the exact calculations. The offer accepting machinery operates independently from the offer making machinery - but not vice versa - this may mean that better deals could have been struck under some circumstances.

\section{REFERENCES}

Bulow, J. and Klemperer, P. (1996). Auctions versus negotiations. American Economic Review, 86(1):180-194.

Castro-Schez, J., Jennings, N., Luo, X., and Shadbolt, N. (2004). Acquiring domain knowledge for negotiating agents: a case study. International Journal of HumanComputer Studies, 61(1):3 - 31

Debenham, J. (2004). A bargaining agent aims to 'play fair'. In proceedings Twenty-fourth International Conference on Innovative Techniques and Applications of Artificial Intelligence, pages 173-186. Springer-Verlag: Heidelberg, Germany.

Faratin, P., Sierra, C., and Jennings, N. (2003). Using similarity criteria to make issue trade-offs in automated negotiation. Journal of Artificial Intelligence, 142(2):205-237.

Halpern, J. (2003). Reasoning about Uncertainty. MT Press.

Jaynes, E. (1957). Information theory and statistical mechanics: Part I. Physical Review, 106:620-630.

Kraus, S. (2001). Strategic Negotiation in Multiagent Environments. MIT Press.

MacKay, D. (2003). Information Theory, Inference and Learning Algorithms. Cambridge University Press.

Muthoo, A. (1999). Bargaining Theory with Applications. Cambridge UP.

Myerson, R. and Satterthwaite, M. (1983). Efficient mechanisms for bilateral trading. Journal of Economic Theory, 29:1-21.

Neeman, Z. and Vulkan, N. (2000). Markets versus negotiations. Technical report, Center for Rationality and Interactive Decision Theory, Hebrew University, Jerusalem.

Osborne, M. J. and Rubinstein, A. (1990). Bargaining and Markets. Academic Press.

Pietra, S. D., Pietra, V. D., and Lafferty, J. (1997). Inducing features of random fields. IEEE Transactions on Pattern Analysis and Machine Intelligence, 19(2):380393.

Ramchurn, S., Jennings, N., Sierra, C., and Godo, L. (2003). A computational trust model for multi-agent interactions based on confidence and reputation. In Proceedings 5th Int. Workshop on Deception, Fraud and Trust in Agent Societies.

Sandholm, T. and Vulkan, N. (1999). Bargaining with deadlines. In Proceedings of the National Conference on Artificial Intelligence (AAAI).

Sierra, C. and Debenham, J. (2005). An information-based model for trust. In Dignum, F, Dignum, V., Koenig, S., Kraus, S., Singh, M., and Wooldridge, M., editors, Proceedings Fourth International Conference on Autonomous Agents and Multi Agent Systems AAMAS2005, pages 497 - 504, Utrecht, The Netherlands. ACM Press, New York. 


\title{
ICEIS 2006
}

Proceedings of the

Eighth International Conference on

Enterprise Information Systems

Artificial Intelligence and Decision Support Systems

Paphos, Cyprus

May $23-27,2006$

Organized by

INSTICC - Institute for Systems and Technologies of Information, Control and Communication

Sponsored by Cyprus Computer Society

\author{
Co-organized by \\ University of Cyprus
}

Aristotle University of Thessaloniki

Athens University of Economics and Business

Cyprus Computer Society 


\title{
Copyright $\mathbb{C}$ INSTICC - Institute for Systems and Technologies of Information, Control and Communication \\ All rights reserved
}

Edited by Yannis Manolopoulos, Joaquim Filipe, Panos Constantopoulos and José Cordeiro

\author{
Printed in Portugal \\ ISBN: 972-8865-42-2 \\ Depósito Legal: 240668/06 \\ http://www.iceis.org \\ secretariat@iceis.org
}

ISBN (13 digits): 978-972-8865-42-9 


\section{BRIEF CONTENTS}

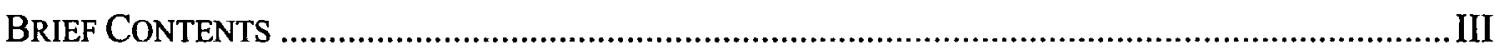

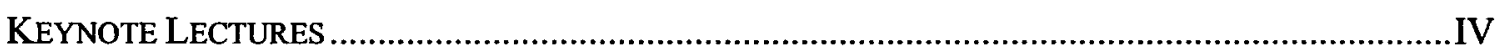

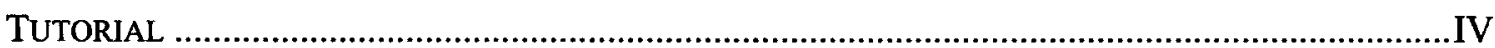

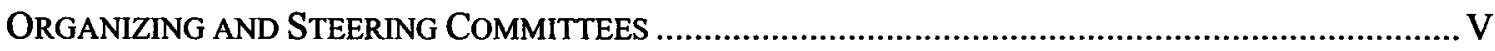

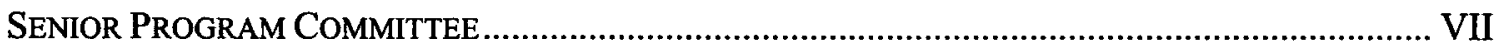

REGULAR PROGRAM COMMITTEE ..................................................................................... VII

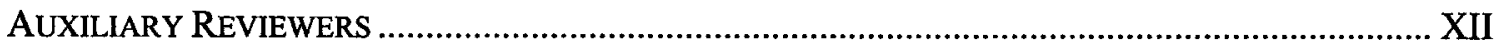

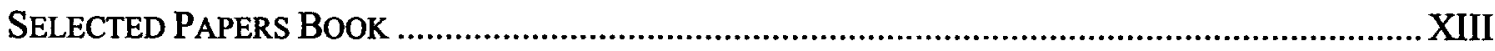

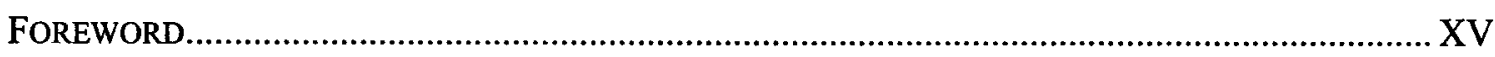

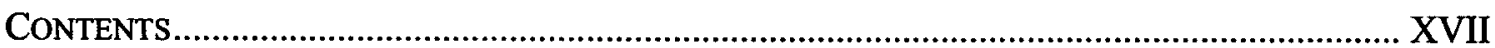




\section{CONTENTS}

\section{INVITED SPEAKERS}

\section{KEYNOTE LECTURES}

HUMAN ACTIVITY RECOGNITION - A GRAND CHALLENGE

IS-6

Jake $K$ Agganval

P2P SEMANTIC MEDIATION OF WEB SOURCES

IS-7

Georges Gardarin, Florin Dragan and Laurent Yeb

BIOMETRIC RECOGNITION: HOW DO I KNOW WHO YOU ARE?

IS-17

Anil K Jain

REFLEXIVE COMMUNITY INFORMATION SYSTEMS

IS-19

Mattbias Jarke

DATA MANAGEMENT IN P2P SYSTEMS: CHALLENGES AND RESEARCH ISSUES

IS-21

Hermann Maurer

ON UTULIZING ATTRIBUTE CARDINALITY MAPS TO ENHANCE QUERY OPTIMIZATION IN THE ORACLE DATABASE SYSTEM

Jobn Oommen and Jing Chen

\section{TUTORIAL}

NEURAL NETWORKS AND BUSINESS APPLICATIONS: BUSINESS INTELLIGENCE

Pedro Henrique Gouvea Coelho and Luiz Biondi Neto

IS-39 


\section{ARTIFICIAL INTELLIGENCE AND DECISION SUPPORT SySTEMS}

\section{FULL PAPERS}

SEMI INTERACTIVE METHOD FOR DATA MINING

Lydia Boudjeloud and François Poulet

SIMILARITY MEASURES FOR SKILL-PROFILE MATCHING IN ENTERPRISE KNOWLEDGE MANAGEMENT

Ernst Biesalski and Andreas Abecker

A DISTRIBUTED ALGORITHM FOR COALITION FORMATION IN LINEAR PRODUCTION DOMAIN

Chattrakul Sombattheera and Aditya Gbose

A FOUNDATION FOR INFORMED NEGOTIATION

John Debenbam and Simeon Simoff

AROUND THE EMPIRICAL AND INTEN'TIONAL REFERENCES OF AGENT-BASED

SIMULATION IN THE SOCIAL SCIENCES

Nuno David and Helder Coelho

SOURCE SENSITIVE ARGUMENTATION SYSTEM

Chee Fon Chang, Peter Harvey and Aditya Ghose

INCREMENTAL PROCESSING OF TEMPORAL OBSERVATIONS IN SUPERVISION AND DLAGNOSIS OF DISCRETE-EVENT SYSTEMS

Gianfranco Lamperti and Marina Zanella

IMPLEMENTATION STRATEGIES FOR “EQUATION GURU” - A USER FRIENDLY

INTELLIGENT ALGEBRA TUTOR

Senay Kafkas, Zeki Bayram and Huseyin Yaratan

INTEGRATING FUZZY LOGIC IN ONTOLOGIES

Silvia Calegari and Davide Ciucci

KNOWLEDGE ENGINEERING USING THE UML PROFILE - ADOPTING THE MODEL-DRIVEN ARCHITECTURE FOR KNOWLEDGE-BASED SYSTEM DEVELOPMENT Mobd Syazpan Abdullah, Richard Paige, Ian Benest and Cbris Kimble

A KNOWLEDGE-BASED REVERSE DESIGN SYSTEM FOR DECLARATIVE SCENE MODELING

Vassilios Golfinopoulos, Vassilios Stathopoulos, George Miaoulis and Dimitri Plemenos

COLLABORATTVE FILTERING BASED ON CONTENT ADDRESSING

Shlomo Berkovsky, Yaniv Eytani and Lamy Manevitz.

KNOWLEDGE-BASED MODELING AND NATURAL COMPUTING FOR COORDINATION IN PERVASIVE ENVIRONMENTS

Michael Cebulla

PERSONALIZED INCENTIVE PLANS THROUGH EMPLOYEE PROFILING

Silverio Petruzzellis, Oriana Licchelli, Ignazio Palmisano, Giovanni Semeraro, Valeria Bavaro and Cosimo Palmisano

A LOGIC-BASED APPROACH TO SEMANTIC INFORMATION EXTRACTION

Massimo Ruffolo and Marco Manna 
ONTOLOGY-DRIVEN INFORMATION INTEGRATION - NETWORKED ORGANISATION CONFIGURATION

Alexander Smimov, Tatiana Levasbova and Nikolay Sbilov

\section{SHORT PAPERS}

BENEFICIAL SEQUENTIAL COMBINATION OF DATA MINING ALGORITHMS Matbias Goller, Markus Humer and Michael Scbrefl

DATA MINING AS A NEW PARADIGM FOR BUSINESS INTELLIGENCE IN DATABASE MARKETING PROJECTS

Filipe Pinto, Pedro Gago and Manuel Filipe Santos

MULTI-CRITERIA EVALUATION OF INFORMATION RETRIEVAL TOOLS

Nishant Kumar, Jan Vanthienen, Jan De Beer and Marie-Francine Moens

DYNAMIC REPRESENTATION OF INFORMATION FOR A DECISION SUPPORT SYSTEM Thierry Galinho, Michel Coletta, Patrick Person and Frédéric Serin

COALITION FORMATION WITH UNCERTAIN TASK EXECUTION

Hosam Hanna

A LOAD BALANCING SCHEDULING APPROACH FOR DEDICATED MACHINE CONSTRAINT

Arthur M. D. Shr, Alan Liu and Peter P. Chen

LOGICRUNCHER - A LOGISTICS PLANNING AND SCHEDULING DECISION SUPPORT SYSTEM FOR EMERGING EMS AND 3PL BUSINESS PRACTICES

Raymund J. Lin, Jack Huang, Norman Sadeh-Koniecpol and Benjamin Tsai

UTILIZATION OF CASE-BASED REASONING IN AUDITING - DETERMINING THE AUDIT FEE

Robert Zenzerovic

FREQUENCY CALIBRATIONS WITH CONVENTIONAL TIME INTERVAL COUNTERS VIA GPS TRACEABILITY

Juan José González de la Rosa, Isidro Lloret, Carlos Garcia Puntonet, Juan Manuel Gómiz, Antonio Moreno, Matias Liñán and Victor Pallarés

DISCOVERING THE STABLE CLUSTERS BETWEEN INTERESTINGNESS MEASURES

Xuan-Hiep Huynh, Fabrice Guillet and Henri Briand

APPLICATION OF THE ROUGH SET METHOD FOR EVALUATION OF STRUCTURAL FUNDS PROJECTS

Tadeusq A. Grzeszcoyle

EFFICIENT MANAGEMENT OF NON REDUNDANT RULES IN LARGE PATTERN BASES: A BITMAP APPROACH

François Jacquenet, Cbristine Largeron and Cédric Udréa

A SEMI-AUTOMATED QUALITY ASSURANCE TOOLBOX FOR DIAGNOSTIC RADIOLOGICAL IMAGING

Christodoulos Constantinou, Andreas Grondoudis, Andreas Cbristoforou, Cbristakis Constantinides and Andreas Lanitis

DECISION SUPPORT SYSTEM FOR BREAST CANCER DIAGNOSIS BY A META-LEARNING APPROACH BASED ON GRAMMAR EVOLUTION

Albert Formells-Herrera, Elisabet Golobardes-Ribé, Ester Bernadó-Mansilla and Joan Marti-Bonmatí 
PREDICTING CARDIOVASCULAR RISKS - USING POSSUM, PPOSSUM AND NEURAL NET TECHNIQUES

Thuy Nguyen Thi Thu and Darry/ N. Davis

VARIOUS PROCESS WIZARD FOR INFORMATION SYSTEMS - USING FUZZY PETRI NETS FOR PROCESS DEFINITION

Jaroslav Prochazka, Jaroslav Knybel and Cyril Klimes

DESIGN AND IMPLEMENTATION OF A FUZZY EXPERT DECISION SUPPORT SYSTEM FOR VENDOR SELECTION - CASE STUDY IN OIEC IRAN(OIL INDUSTERIAL ENGINEERING AND CONSTRUCTION)

Maryam Ramezani and G. A. Montazer

FUZZY INTERVAL NUMBER (FIN) TECHNIQUES FOR CROSS LANGUAGE INFORMATION RETRIEVAL

Catherine Marinagi, Theodoros Alevizos, Vassilis G. Kaburlasos and Christos Skourlas

AUTOMATIC IDENTIFICATION OF NEGATED CONCEPTS IN NARRATIVE CLINICAL REPORTS

Lior Rokach, Roni Romano and Oded Maimon

AN EXTENDABLE JAVA FRAMEWORK FOR INSTANCE SIMILARITIES IN ONTOLOGIES

Mark Hefke, Valentin Zacharias, Andreas Abecker, Qingli Wang, Emst Biesalski and Marco Breiter

SELECTING AND STRUCTURING SEMANTIC RESOURCES TO SUPPORT SMES KNOWLEDGE COMMUNITIES

António L ucas Soares, Manuel Moreira da Silva and Dora Simöes

DEVELOPMENT OF SUMMARIES OF CERTAIN PATTERNS IN MULTI-BAND SATELLITE IMAGES

Hema Nair

\section{POSTERS}

BUILDING COMPETITIVE ADVANTAGE VIA CRM BASED ON DATA WAREHOUSE AND DATA MINING

Jiejun Huang, Wei Cui and Yanbin Yuan

DLAGNOSIS OF DEMENTIA AND ITS PATHOLOGIES USING BAYESIAN BELIEF NETWORKS

Julie Cowie, Lloyd Oteniya and Richard Coles

DECISION SUPPORT ON THE MOVE - MOBILE DECISION MAKING FOR TRIAGE MANAGEMENT

Julie Conie and Paul Godley

SIMULATION MODELLING OF IRON ORE PRODUCTION SYSTEM AND QUALITY MANAGEMENT

Jim E. Everett

METHOD FOR DRAWING UP A ROAD MAP THAT CONSIDERS THE SYNERGY EFFECT AND RISK FOR IT INVESTMENT

Tadasuke Nakagawa, Shigeyuki Tani, Masabaru Akatsu and Noribisa Komoda

THE USE OF THE NATURAL LANGUAGE UNDERSTANDING AGENTS WITH CONCEPTUAL MODELS

Olegas Vasilecas and Algirdas Laukcaitis

XX 
QUALITY LEARNING OBJETCS MANAGEMENT - A PROPOSAL FOR E-LEARNING SYSTEMS

Erla Morales, Angela Barrón and Francisco Garcia

INTRODUCING INTELLIGENT AGENTS TO OUTSOURCING

Hemal Kothari, Bermadette Sharp, Luke Ho and Anthony Atkins

KNOWLEDGE MANAGEMENT FOR RAMP-UP - APPROACH FOR KNOWLEDGE

MANAGEMENT FOR RAMP-UP IN THE AUTOMOTIVE INDUSTRY

Sven Thiebus, Ulrich Benger and Ralf Kretzscbmann

SADIM: AN AID SYSTEM FOR MANAGEMENT ENGINEERING DIAGNOSIS USING KNOWLEDGE EXTRACTION AND MATCHING TECHNIQUES

Jamel Kolsi, Lamia Hadrich Belguith, Mansour Mrabet and Abdelmajid Ben Hamadou

KNOWLEDGE MANAGEMENT NOVEL APPLICATIONS

Vasso Stylianou and Andreas Sawa

TOWARDS A COMPLETE DATA MANAGEMENT FRAMEWORK BASED ON INTELLIGENT AGENTS

Iulian Alexandru Negroiu, Octarian Paul Rotaru and Mircea Petrescu

A MULTI-AGENT ARCHITECTURE FOR MOBILE SELF-TRAINING

Mosrad Ennaji, Hadhoum Bouhachour and Patrick Gravé

LOCATING KNOWLEDGE THROUGH AUTOMATED ORGANIZATIONAL CARTOGRAPHY [AUTOCART]

Mounir Kebal, Sandrine Crener and Patrice Sargenti

GEOSPATIAL SEMANTIC QUERY BASED ON CASE-BASED REASONING SYSTEM

Kay Khaing Win

SOME SPECIAL HEURISTICS FOR DISCRETE OPTIMIZATION PROBLEMS

Boris Melnikov, Alexey Radionov and Viktor Gumajwnov

A METHOD BASED ON THE ONTOLOGY OF LANGUAGE TO SUPPORT CLUSTERS' INTERPRETATION

Wagner Francisco Castilbo, Gentil José de Lucena Filbo, Hércules Antonio do Prado and Edilson Ferneda 